\title{
Novel protocol to identify true hybrids in normal oleate $x$ high oleate crosses in peanut
}

\author{
Chuan Tang Wang ${ }^{1} \square \cdot$ Shan Lin $\mathrm{Yu}^{1} \cdot$ Shu Wei Zhang ${ }^{1} \cdot$ Xiu Zhen Wang ${ }^{1}$ \\ Yue Yi Tang ${ }^{2}$. Jian Cheng Zhang ${ }^{2}$ Dian Xu Chen ${ }^{3}$ \\ 1 Shandong Peanut Research Institute, Qingdao, P.R. China \\ $\triangle$ Corresponding author: chinapeanut@126.com \\ Received April 27, 2010 / Accepted July 29, 2010 \\ Published online: September 15, 2010 \\ (C) 2010 by Pontificia Universidad Católica de Valparaíso, Chile
}

\begin{abstract}
A novel hybrid identification protocol was developed for $F_{0: 1}$ peanut seeds resulting from crosses between normal oleate cultivars with wild type $F A D 2 B$ gene and high oleate genotypes with an $A$ insertion in $F A D 2 B$ gene. Presence of a series of overlapped peaks in trace file of the PCR product amplified with bF19/R1 primers was an indication of hybridity. This protocol may facilitate high oleate breeding and genetic studies in peanut.
\end{abstract}

Keywords: identification, NIRS, PCR, peanut, true hybrid

\section{INTRODUCTION}

Preferred by food processors and consumers, high oleate peanuts have prolonged shelf life and may decrease bad low density lipoprotein (LDL) cholesterol, while maintaining beneficial high density lipoprotein (HDL) cholesterol (O'Byrne et al. 1997). High oleate is likely to become an indispensable trait of the next generation peanut varieties. Though high in oleate content, the currently available materials have productivity far from acceptable. Incorporating this valuable trait in high yielding adapted cultivars is the endeavor of many peanut breeders worldwide. A simple protocol for identification of true peanut hybrids in normal oleate $\mathrm{x}$ high oleate crosses will undoubtedly facilitate this process.

\section{MATERIALS AND METHODS}

\section{Peanut material}

To breed high oleate, Virginia-type peanut varieties for international market and high oleate, high yielding peanut for domestic consumption, four crosses were made between high oleate donors, FB4 and CTWE, 2 peanut lines developed by us, and normal oleate, high yielding peanut cultivars, Huayu 31, Huayu 22 and 08-test-A2 


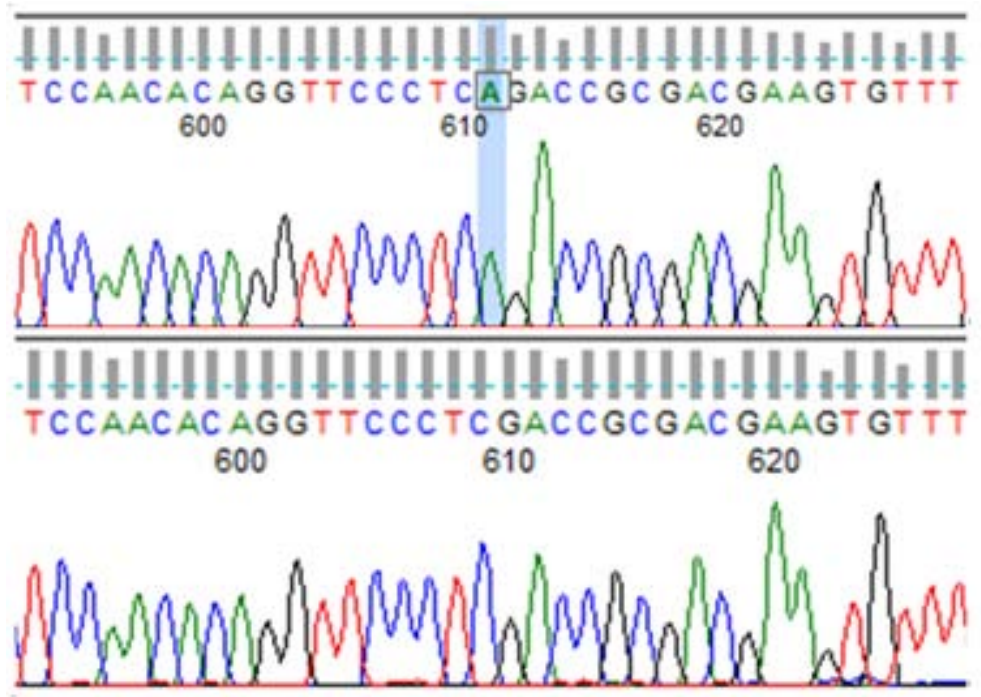

Fig. 1 Difference in FAD2B/fad2b sequence between high oleate (top) and normal oleate genotypes (bottom), note an A insertion in high oleate fad2b sequence.

(Table 1). Crossing was carried out by workers with minimal training according to the standard procedure described by Yu et al. (2008). Ten seeds ( $F_{0: 1}$, hybridity unknown) were randomly selected from each cross for hybrid identification. Seed serial numbers 1-10, 11-20, 21-30 and 31-40 were from Huayu 31 x FB4, Huayu 22 x CTWE, 08-testA2 x CTWE and 08-test-A2 x FB4, respectively.

\section{Cloning and sequencing of $F A D 2 B / f a d 2 B$ gene in parental genotypes}

DNA templates were prepared from immature leaflets in peanut seeds as described by Wang et al. (2009). Gene-specific PCR primers, bF19/R1 (Patel et al. 2004), were used to amplify the FAD2B/fad2B gene. The PCR mixture $(50 \mu \mathrm{l})$ contained $25 \mu \mathrm{l}$ of Tiangen $2 \times$ Taq platinum Master Mix (Tiangen Biotech, Beijing, China), $5 \mu$ of DNA template, $2 \mu \mathrm{l}$ of forward and reverse primers $(10 \mu \mathrm{M})$ each. The PCR program was $95^{\circ} \mathrm{C}$ for $6 \mathrm{~min}$, followed by 35 cycles of $94^{\circ} \mathrm{C}$ for $30 \mathrm{sec}, 53^{\circ} \mathrm{C}$ for $1 \mathrm{~min}$, and $72^{\circ} \mathrm{C}$ for $2 \mathrm{~min}$, and a final extension of $74^{\circ} \mathrm{C}$ for $4 \mathrm{~min}$. The PCR program was run on a Biometra Tgradient thermal cycler (Biometra, Göttingen, Germany). The PCR products were purified, ligated into a pBS-T vector, and used in heat shock transformation with chemically competent TOP10 E. coli cells (Tiangen Biotech, Beijing, China). White colonies harboring plasmids with inserts of expected size identified by colony PCR were sequenced on an ABI 3730XL DNA sequence using the M13 forward and reverse primers. Translation and alignment of DNA sequences were completed with the Lasergene ${ }^{\text {TM }}$ DNAStar package (DNASTAR, Madison, USA).

\section{Amplification of $F A D 2 B / f a d 2 B$ gene to identify true hybrids}

PCR templates were prepared from a slice of cotyledonary tissue (Yu et al. 2010). The PCR mixture $(50 \mu \mathrm{l})$ consisted of $5 \mu \mathrm{l}$ of DNA template, $2 \mu \mathrm{l}$ of bF19/R1 $(10 \mu \mathrm{M})$ primers each (Patel et al. 2004), and $25 \mu$ of Tiangen 2 x Taq PCR Master Mix 
(Tiangen Biotech, Beijing). The thermal cycling profile and PCR machine were the same as mentioned above. After checking for presence of amplification bands on agarose gel, the PCR products were purified and then sequenced on an ABI 3730XL DNA sequencer using the bF19 primer. The trace files were viewed with Finch TV1.4.0 (Geospiza Inc., Seattle, USA).

\section{RESULTS AND DISCUSSION}

\section{Cloning and sequencing of $F A D 2 B / f a d 2 B$ gene in parental genotypes}

With bF19/R1 primers, all of the parental genotypes, viz., normal oleate peanut varieties, Huayu 22, Huayu 31 and 08-test-A2, and high oleate peanut lines, FB4 and CTWE, produced PCR products of expected size. Positive colonies were obtained through colony PCR.

Multiple alignment of the resultant DNA sequences and the Arachis hypogaea L. FAD2B sequence deposited in GenBank (GenBank acc\# AF272950) showed that in high oleate parental lines, there was an A insertion immediately after the 521 base counting from the bF19 primer, corresponding to the position after 441 in coding region of the $F A D 2 B$ gene (Figure 1 ), which caused a frameshift and a truncated protein. The mutant type of $F A D 2 B$, fad $2 B$, was the same as those described by $Y u$ et al. (2008) and Chu et al. (2009).

\section{Amplification of $F A D 2 B / f a d 2 B$ gene(s) to identify true hybrids}

With bF19/R1 primers, all the 40 seeds from the 4 crosses yielded PCR products of expected size. Two types of trace files were shown in Figure 2 and Figure 3.

Huayu 31, Huayu 22 and 08-test-A2 were confirmed to have wild type FAD2B genes, whereas FB4 and CTWE had a loss-of-function FAD2B gene (fad2B). Characterized by presence of a series of overlapped peaks in trace files, true hybrids $\left(F_{0: 1}\right)$ can be easily identified by visual inspection of trace files (Figure 2 and Figure 3). Among the 40 seeds tested with sequencing, 4, 5, 5 and 1 seeds were identified as true hybrids for Huayu 31 x FB4, Huayu 22 x CTWE, 08-test-A2 x CTWE and 08-test-A2 x FB4, respectively, and the rest seeds were false hybrids (Table 1 ). On average, true hybrids accounted for $37.5 \%$ of the $F_{0: 1}$ seeds.

Table 1. Direct sequencing of PCR products revealed true hybrids in normal oleate $\mathbf{x}$ high oleate crosses in peanut.

\begin{tabular}{lcc}
\hline Cross $\left(+\times{ }^{-}\right)$ & $\begin{array}{c}\text { Serial no. of seeds with } \\
\text { overlapped peaks } \\
\text { (true hybrids) }\end{array}$ & $\begin{array}{c}\text { Serial no. of seeds without } \\
\text { overlapped peaks (selfs) }\end{array}$ \\
\hline Huayu 31 x FB4 & $1,3,5,6$ & $2,4,7,8,9,10$ \\
\hline Huayu 22 x CTWE & $11,12,13,16,20$ & $14,15,17,18,19$ \\
08-test-A2 x CTWE & $21,22,25,28,30$ & $23,24,26,27,29$ \\
08-test-A2 x FB4 & 31 & $32,33,34,35,36,37,38,39,40$ \\
\hline
\end{tabular}


For detection of wild and mutant type $F A D 2 A / F A D 2 B$ genes, cleaved amplified polymorphic sequences (CAPS) markers for both homologous genes (Chu et al. 2007; Chu et al. 2009) and real-time PCR marker for wild and mutant alleles of FAD2B (Barkley et al. 2010) have also been developed. These protocols need restriction enzymes or a qPCR machine. More recently, Chen et al. (2010) reported development of a simple allele-specific PCR assay for both genes. However, in our lab, conducted with a PCR machine of different type, this assay was not as successful as described by the developers. In contrast, our protocol to detect mutant allele of $F A D 2 B$ is straightforward and more reliable, as long as sequencing facilities are readily accessible. Since there are many companies providing sequencing service and the cost per run is constantly going down, the present protocol suits the need from poorly equipped labs without a DNA sequencer.

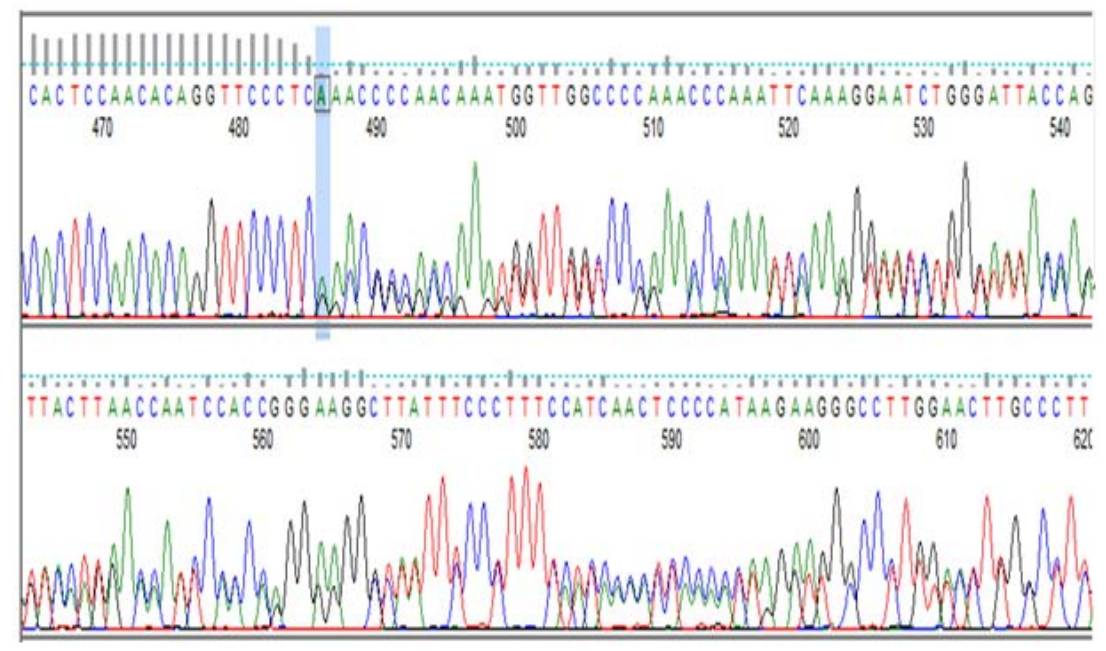

Fig. $2 \mathrm{~A}$ true $\mathrm{F}_{0: 1}$ hybrid was identified after direct sequencing of the FAD2B/fad2B PCR product, note a series of overlapped peaks beginning from the shaded base.

True hybrids in peanut may also be identified by morphological features, though it is not always reliable, and sometimes time-consuming (Gomez et al. 2008). Other molecular tools, such as isozymes profiling and DNA marker system, have been successfully used to distinguish true hybrids from selfs (Lacks and Stalker, 1993; Gomez et al. 2008; Li et al. 2009); for a specific cross combination, screening for informative isozymes/primers are absolutely necessary. Our protocol, however, is widely applicable to crosses between normal oleate cultivars and high oleate genotypes with 441 442ins $A$ in $F A D 2 B$ gene, since no normal oleate peanut genotype with such an insertion in FAD2B gene has thus far been identified in world peanut germplasm collections (Chen et al. 2010). It seems that there is no need to change primers and PCR thermal cycling profiles for different cross combinations.

The present protocol has been successfully used to establish $F_{2}$ segregating populations ( $F_{1: 2}$ seeds) resulting from normal oleate $x$ high oleate crosses, and robust near infrared spectroscopy (NIRS) calibration equations have been developed for predicting oleic $\left(R^{2}=97.20 \%\right)$, linoleic $\left(R^{2}=96.90 \%\right)$, and palmitic acids $\left(R^{2}=\right.$ 


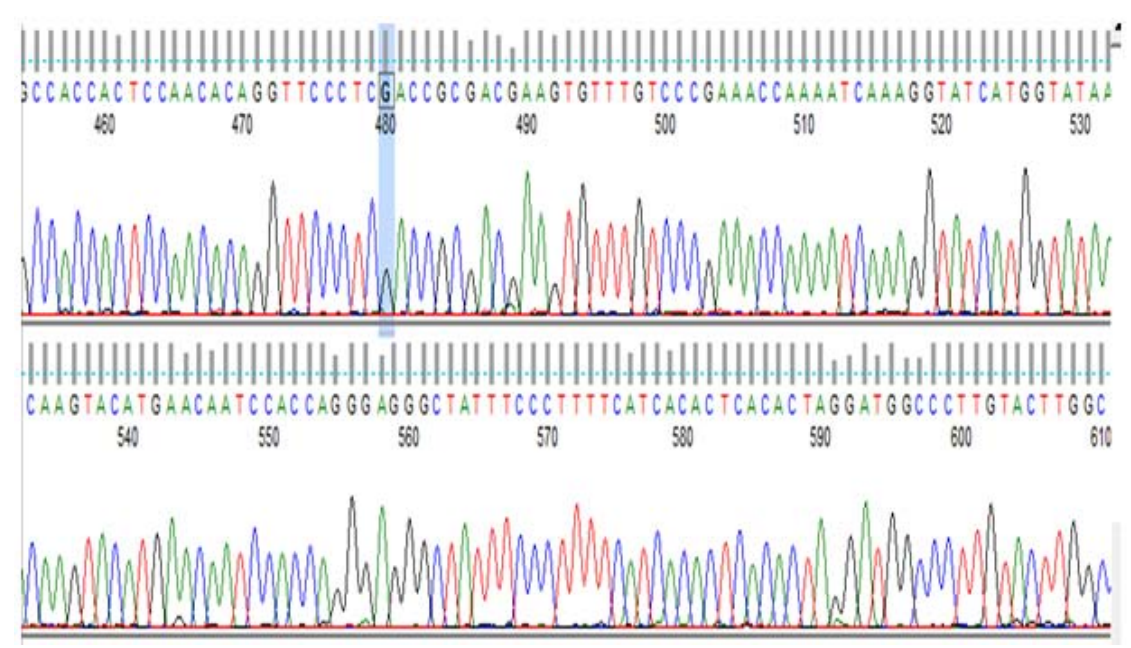

Fig. 3 A false $F_{0: 1}$ hybrid was identified after direct sequencing of the FAD2B/fad2B PCR product, note no overlapped peaks beginning from the shaded base.

93.39\%) in intact single peanut seeds (Chuan Tang Wang unpublished). The hybridity of the $F_{0: 1}$ seeds was supported by NIRS analysis. Oleate contents in the true $F_{0: 1}$ seeds, as predicted by NIRS, were essentially intermediate relative to oleate in parental genotypes (data not shown), an indication that NIRS may have some potential in this regard, even though variation in oleate content of single intact peanut seeds of a specific cultivar does exist.

Loss-of-function FAD2A and FAD2B genes ( $f a d 2 A$ and $f a d 2 B$ ) are considered to be the major genes responsible for high oleate trait of peanut, but there are also other genes that influence oleate content (Isleib et al. 2006). The present protocol is of significance to studies on the genetics of high oleate in peanut and the effects of $F A D 2 A, F A D 2 B$ and additional genes, and is helpful to peanut breeders interested in developing high oleate peanut cultivars as well. Of course, this protocol can also be used to appraise the performance of workers in hybridizing peanuts.

Financial support: The authors thank support from the earmarked fund for Modern Agroindustry Technology Research System (MATRS) Peanut Program (Grant No. nycytx-19), Ministry of Agriculture, China, China Natural Science Foundation (Grant No. 30300224), 863 New and High Technology Project (Grant No. 2006AA10A114), New and High Technology Innovation Foundation of Shandong Academy of Agricultural Sciences (Grant No. 2006 YCX013), and Young Scientists Foundation of Shandong Academy of Agricultural Sciences (Grant No.2007YQN007).

\section{REFERENCES}

BARKLEY, Noelle A.; CHAMBERLIN, Kelly D. Chenault; WANG, Ming Li and PITTMAN, Roy N. Development of a real-time PCR genotyping assay to identify high oleic acid peanut (Arachis hypogaea L.). Molecular Breeding, March 2010, vol. 25, no. 3, p. 541-548. [CrossRef] 
CHEN, Zhenbang; WANG, Ming Li; BARKLEY, Noelle A. and PITTMAN, Roy N. A simple allelespecific PCR assay for detecting FAD2 alleles in both $A$ and $B$ genomes of the cultivated peanut for high-oleate trait selection. Plant Molecular Biology Reporter, September 2010, vol. 28, no. 3, p. 542-548. [CrossRef]

CHU, Y.; RAMOS L.; HOLBROOK, C.C. and OZIAS-AKINS, P. Frequency of a loss-of-function mutation in oleoyl-PC desaturase $(a h F A D 2 A)$ in the mini-core collection of the U.S. Peanut Germplasm Collection. Crop Science, November 2007, vol. 47, no. 6, p. 23722378. [CrossRef]

CHU, Ye; HOLBROOK, C. Corley and OZIAS-AKINS, Peggy. Two alleles of ahFAD2B control the high oleic acid trait in cultivated peanut. Crop Science, November 2009, vol. 49, no. 6, p. 2029-2036. [CrossRef]

GOMEZ, S.M.; DENWAR, N.N.; RAMASUBRAMANIAN, T.; SIMPSON, Charles E.; BUROW, G.; BURKE, J.J.; PUPPALA, N. and BUROW, M.D. Identification of peanut hybrids using microsatellite markers and horizontal polyacrylamide gel electrophoresis. Peanut Science, July 2008, vol. 35, no. 2, p. 123-129. [CrossRef]

ISLEIB, T.G.; WILSON, R.F. and NOVITZKY, W.P. Partial dominance, pleiotropism and epistasis in the inheritance of the high-oleate trait in peanut. Crop Science, May 2006, vol. 46, no. 3, p. 1331-1335. [CrossRef]

LACKS, G.D. and STALKER, H.T. Isozyme analysis of Arachis species and interspecific hybrids. Peanut Science, July 1993, vol. 20, no. 2, p. 76-81. [CrossRef]

LI, Shuang Lin; WANG, Hui; REN, Yan; SHI, Yan-Mao; HE, Guo-Hao; YU, Shan-Lin and YUAN Mei. Identification of peanut hybrids using SSR markers with fluorescence labeled M13tailed primer. Journal of Peanut Science, 2009, vol. 38, no. 4. p. 35-38.

O'BYRNE, Dawn J.; KNAUFT, David A. and SHIREMAN, Rachel B. Low fat monounsaturated rich diets containing high oleic peanuts improve serum lipoprotein profiles. Lipids, July 1997, vol. 32, no. 7, p. 687-695. [CrossRef

PATEL, M.; JUNG, S.; MOORE, K.; POWELL, G.; AINSWORTH, C. and ABBOTT, A. Higholeate peanut mutants result from a MITE insertion into the FAD2 gene. TAG Theoretical and Applied Genetics, May 2004, vol. 108, no. 8, p. 1492-1502. [CrossRef]

WANG, Chuan Tang; WANG, Xiu Zhen; TANG, Yue Yi; ZHANG, Jiang Cheng; YU, Shan Lin; $\mathrm{XU}$, Jian Zhi. and BAO, Zhen Min. A rapid and cheap protocol for preparation of PCR templates in peanut. Electronic Journal of Biotechnology, April 2009, vol. 12, no. 2. [CrossRef]

YU, Shanlin; PAN, Lijuan; YANG, Quingli; MIN, Ping; REN, Zengkai and ZHANG, Hongsheng. Comparison of the $\Delta^{12}$ fatty acid desaturase gene between high-oleic and normal-oleic peanut genotypes. Journal of Genetics and Genomics, November 2008, vol. 35, no. 11, p. 679-685. [CrossRef]

YU, Shu Tao; WANG, Chuan Tang; WANG, Xiu Zhen; TANG, Yue Yi.; CHEN, Dian Xu; ZHANG, Jian Cheng and YU, Shan Lin. Simple method to prepare DNA templates from a slice of peanut cotyledonary tissue for polymerase chain reaction. Electronic Journal of Biotechnology, July 2010, vol. 13, no. 4. [CrossRef] 


\section{How to cite this article:}

WANG, C.T.; YU, S.L.; ZHANG, S.W.; WANG, X.Z.; TANG, Y.Y.; ZHANG, J.C. and CHEN, D.X. Novel protocol to identify true hybrids in normal oleate $x$ high oleate crosses in peanut. Electronic Journal of Biotechnology, September 2010, vol. 13, no. 5. http://dx.doi.org/10.2225/vol13-issue5-fulltext-18 